\title{
Possible mechanism of the formation of the Jichechang ground fissure in Datong, China, based on in-situ observations
}

\author{
Ruichun Liu ${ }^{1,2,3} \cdot$ Chengsheng Yang ${ }^{4}$ Qingliang Wang ${ }^{5}$ Lingyun $\mathrm{Ji}^{5}$
}

Received: 25 August 2020 / Accepted: 23 May 2021 / Published online: 4 July 2021

(c) The Author(s) 2021

\begin{abstract}
The Datong region of China suffers from severe ground fissure (GF) disasters. The Jichechang ground fissure (JGF) is typical among the GFs in Datong and is the most active. To provide scientific guidance for disaster mitigation, understanding the mechanisms governing GF activity in Datong needs to be improved. Here, long-term monitoring data (>10 years) for the JGF are used to study the characteristics of its activity. The results show that the formation of GFs is mainly controlled by concealed faults. The JGF is mainly active in the vertical direction, with a differential vertical displacement 2.5 times greater than the horizontal displacement. The GF activity is periodic, with a periodicity of 320-420 days, which corresponds to the cycle of local agricultural irrigation. The JGF is especially active in June and July. The vertical activity of this fissure also displays a distinct quasi-periodic step-like displacement acceleration with a duration of 18-38 days. Numerical simulations show that irrigation pumping within $10 \mathrm{~km}$ of the JGF has a significant effect on the vertical movement of GFs. These results provide a better understanding of the mechanisms governing GF activity in this area and provide a valuable reference for the study of GFs in other regions.
\end{abstract}

Keywords Datong basin · Ground fissure · Groundwater pumping $\cdot$ Differential displacement $\cdot$ Concealed fault

\section{Introduction}

A ground fissure (GF) refers to the phenomenon in which the continuity of the rock or soil layer is destroyed, usually appearing as a crack on the ground surface (Wang et al. 2000; Ye et al. 2018). The formation of GFs is usually related to the effects of internal and external forces and human activity (Peng 2012; Lu et al. 2013; Liu et al. 2019b). As a geological disaster, GFs not only cause serious damage to various types of engineering structures, such as urban

Chengsheng Yang

yangchengsheng@chd.edu.cn

1 College of Mining Engineering, Taiyuan University of Technology, Taiyuan 030024, China

2 Shanxi Earthquake Agency, Taiyuan 030021, China

3 Continental Rift Valley Dynamics State Observatory of Taiyuan, Taiyuan 030021, China

4 College of Geology Engineering and Geomatics, Chang' an University, Middle Section of Nan Erhuan Road, Xi'an 710054, Shaanxi, China

5 Second Crust Monitoring and Application Center, CEA, Xi' an 710054, China buildings, roads, bridges, and underground pipelines (Peng et al. 2018; Liu et al. 2019a), but also cause many environmental problems including groundwater system damage and the destruction of land (Howard and Zhou 2019). Because GF disasters are common in many countries worldwide, such as the United States, Saudi Arabia, and Mexico, GF formation mechanism and the factors affecting their development have received research attention (e.g., Jachens and Holzer 1982; Holzer 1984, 1991; Bankher and Al-Harthi 1999; Wang et al. 2009, 2016; Pacheco-Martínez et al. 2013).

Tectonic stresses, groundwater exploitation, heavy rainfall, and the combination of these phenomena have been widely recognized as mechanisms responsible for GF formation (Jachens and Holzer 1982; Holzer 1991; Geng and Zhong 2000; Lu et al. 2013, 2020; Pacheco-Martínez et al. 2013; Peng et al. 2013). In addition, methods for monitoring and predicting the development of GFs have been proposed, which have proved important for disaster risk reduction and prevention (e.g., Brunori et al. 2015; Fergason et al. 2015; Yang et al. 2018).

In China, GFs have been recognized as a serious problem since the first case was recorded in Xi' an in the 1950s. At present, more than 6000 GFs have been recorded in China 
(Wang et al. 2001; Howard and Zhou 2019). The Fenwei Basin is a particularly important extensional fault zone in mainland China, with the largest number of GFs in the country. The Fenwei Basin GFs are extremely active and have caused economic losses amounting to tens of billions of Yuan (Peng et al. 2017). Datong is located at the northern end of the Fenwei Basin (Fig. 1) and since the 1980s, 11 GFs have been discovered here with a total length of $34 \mathrm{~km}$ (Liu et al. 1999; Fan 2003). These GFs extend linearly with an orientation of $\mathrm{N} 30^{\circ} \mathrm{E}-\mathrm{N} 80^{\circ} \mathrm{E}$. Because of their continuous activity, more than 200 buildings, pipelines, and other facilities positioned across the Datong GFs have been destroyed, resulting in significant economic losses (Ren et al. 2004; Peng et al. 2017). This has garnered widespread concern from local governments, and consequently, many investigations have been conducted (Liu et al. 1999; Fan 2003; Ren et al. 2004; Zan 2006; Yang et al. 2014, 2019). However, previous research has mainly focused on the surface impact of GFs through field investigations rather than determining the mechanisms of activation (i.e., causal factors, cyclical patterns, and stress regime). This seriously restricts efforts to predict and mitigate the impacts of GFs in the city.
The Jichechang ground fissure (JGF) is typical of the 11 GFs in Datong and is the most active (Fig. 1). A system to monitor the activity of the JGF was established in 1989, providing high-resolution data on its activity. Here, observational monitoring data collected over a period of more than 10 years are used alongside geological and hydrological data to characterize the activity of the JGF. This has revealed the impact of local agricultural irrigation on GF activity and provides a valuable reference for the study of GF activity in other regions.

\section{Geological setting of the JGF}

The Datong Basin is a narrow Cenozoic faulted basin located toward the northeast of Shanxi Province (Fig. 1). The bedrock uplift area in the north, west, and south of the basin is a mountain at an altitude above $1000 \mathrm{~m}$ which is prone to erosion and denudation. The subsidence area inside the basin is a landform accumulation plain. There are generally piedmont alluvial, piedmont proluvial-impact, and lacustrine plains controlled by piedmont faults, from the edge of

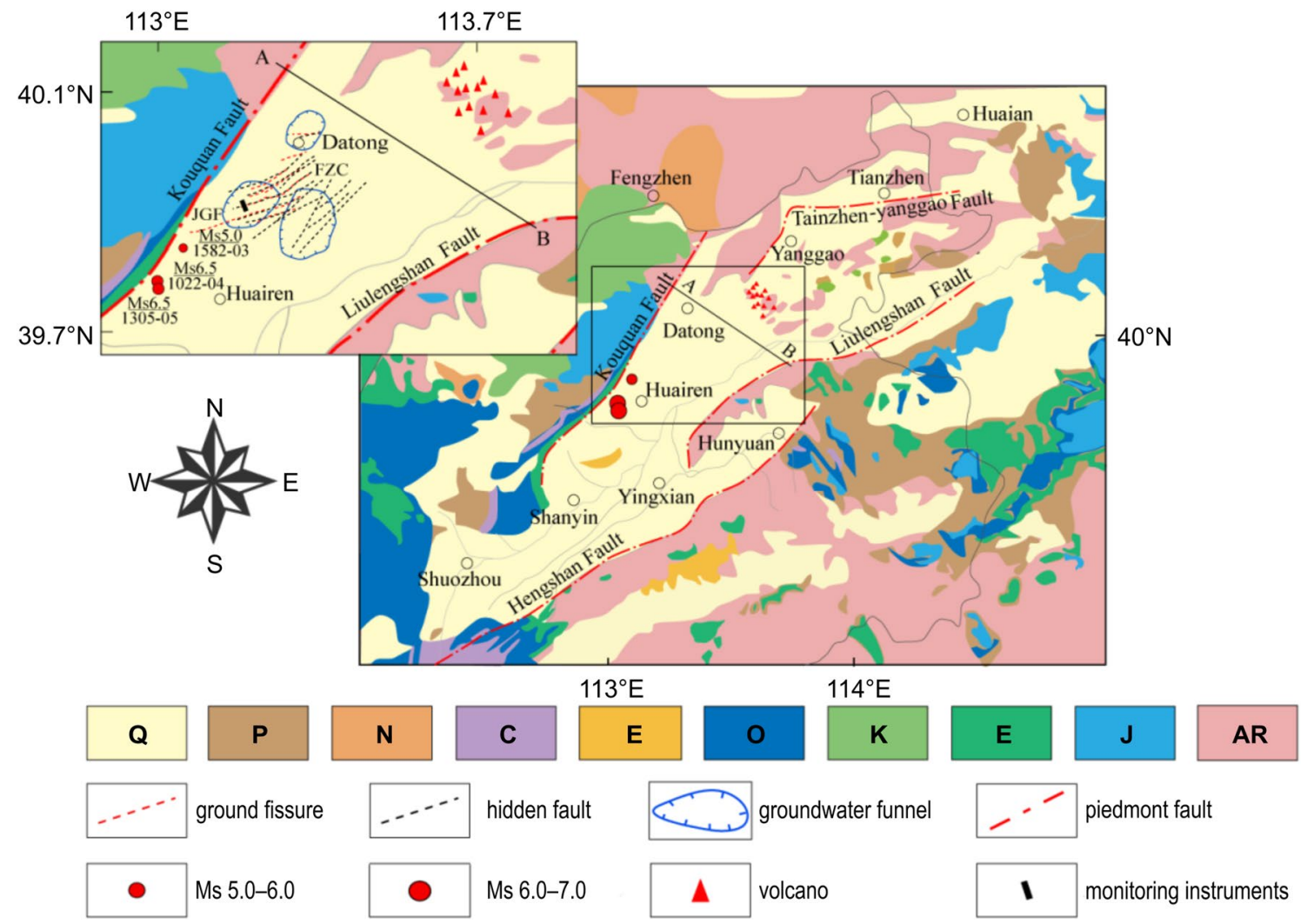

Fig. 1 Geological map of the Datong Basin. The top left inset is the map of Datong City. JGF Jichechang ground fissure, FZC Fangzicun concealed fault. The black solid rectangle represents the location of the JGF monitoring station. The horizontal line "AB" is the location of hydrogeological profile in Fig. 2. The red circles indicate earthquake locations; the upper values adjacent to the red circles indicate the earthquake magnitude and lower values indicate the time of earthquake occurrence in YYYY-MM format 
the basin to the center. The maximum buried depth of the base of the basin is more than $3000 \mathrm{~m}$ (Shanxi Earthquake Agency 2005; Dong et al. 2008; Han et al. 2017). The area of Datong county in the east of the basin is the seat of the famous "Datong Volcano Group", where Cenozoic basalts have been unearthed (Cen 2015). The loess platforms are divided by gullies, in the northern piedmont of Hengshan Mountain to the south of the basin and the piedmont of the eastern Liuleng Mountain to the east of the basin. The development of loess platforms is related to the distribution of piedmont faults (Shanxi Earthquake Agency 2005).

Groundwater occurs in the cracks of the metamorphic rocks, volcanic rocks, and clastic rocks in the bedrock mountainous area around the basin. The aquifer is mainly composed of sand, gravel, and medium-coarse sand, and the depth at which groundwater is available at $20-100 \mathrm{~m}$. In the basin, the most important water-bearing rock group holds loose rock pore water, which is the main aquifer buried at a depth less than $200 \mathrm{~m}$, mostly between 100 and $150 \mathrm{~m}$. The water-bearing rock group is dominated by middle and upper Pleistocene alluvial, an alluvial sandy gravel layer, and multiple thin layers of middle Pleistocene alluvial fine sand. There is an aquiclude layer of clay and sub-clay $50 \mathrm{~m}$ below the surface (Fig. 2). Therefore, above $50 \mathrm{~m}$, there are mostly layers of unconfined aquifers, whereas those below $50 \mathrm{~m}$ are confined aquifers (Guo et al. 2002; Han 2008). The large thickness of unconsolidated sediment in the basin provides an optimal location for the storage and migration of groundwater. The upper and lower aquifers are connected by faults, skylights, and numerous mixed production wells in the basin. Groundwater in the whole basin has a unified hydraulic connection (Dong et al. 2008). The results of a large-scale pumping test showed that the groundwater level in each aquifer within $10 \mathrm{~km}$ of the pumping group wells varied with the process of pumping and the water level recovery (Che and Yu 2004). Groundwater is the only source of water for industrial and agricultural production in Datong City. Long-term overexploitation has led to the continuous decline in groundwater level, the drying of several aquifers, and the abandonment of many mining wells, thereby forming three large settlement funnels in Datong City (Guo et al. 2002; Dong et al. 2008).

Affected by the combined influence of the eastward extrusion of the Qinghai-Tibet Plateau and the westward subduction of the Pacific Plate, the upper mantle uplifted and the low-velocity-high-conductivity layer of the middle crust developed horizontally, which made the upper crust to stretch in the northwest direction, thereby developing a crack along the existing fracture surface forming a shovel-type normal fault at the edge of the Datong Basin. These faults are large in scale and are active, controlling the neotectonic movement in the basin (Cen 2015; Peng et al. 2017). The Kouquan Fault controls the western boundary of the Datong Basin, with a total length of $160 \mathrm{~km}$ (Fig. 1), and has been active since the Late Quaternary (Xu et al. 2011). In addition to the two earthquakes near the fault recorded in the historical data with a magnitude 6 or above, the trench study also found four ancient earthquake relics from the Holocene, with corresponding magnitudes above 7 (Deng et al. 1992; catalogue of strong earthquakes in China, 1995; Xie et al. 2003). There are many buried active faults in the Datong City controlled and influenced by the secondary stress field generated by the Kouquan Fault (Chen and Ye 2002). The length of these buried active faults ranges from 3.5 to $8 \mathrm{~km}$ and their strikes are $\mathrm{N} 30^{\circ} \mathrm{E}-\mathrm{N} 58^{\circ} \mathrm{E}$ ("hidden faults" in Fig. 1), which have serious impacts on the urban planning and construction of Datong City.

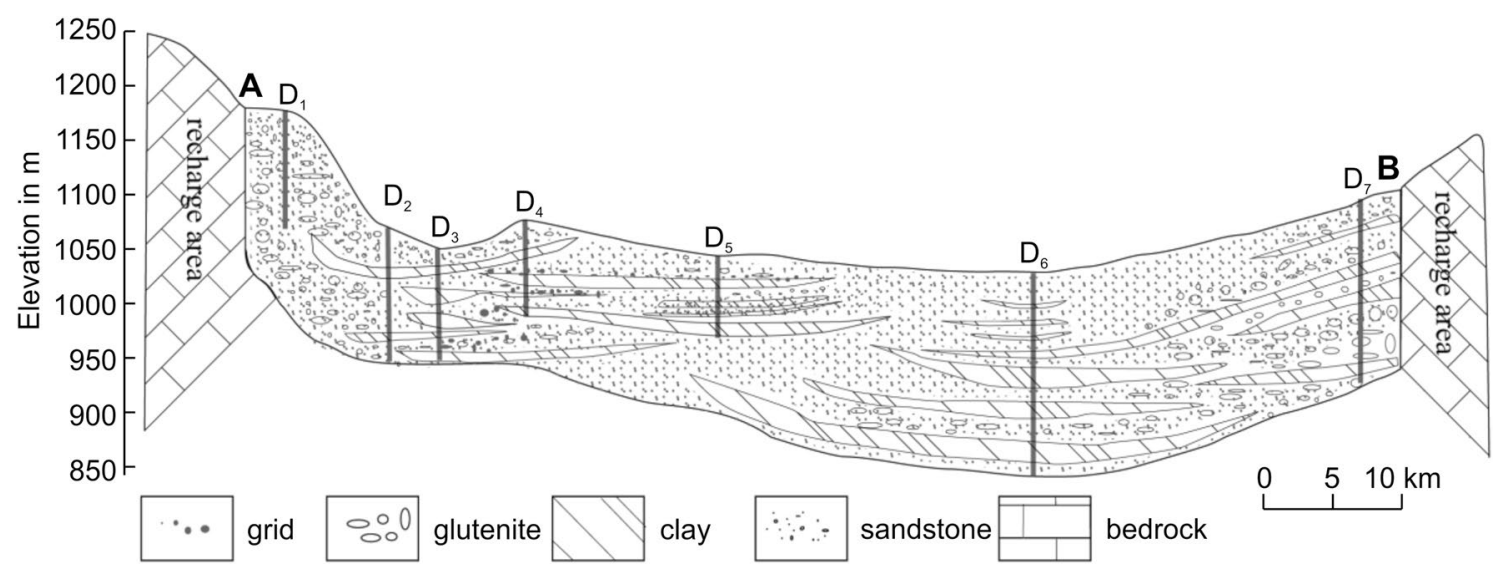

Fig. 2 Hydrogeological profile map of the study area. D1 is located $100 \mathrm{~m}$ southwest of Xiaoshitou Village; D2 is located in Baima Town in the northern suburb of Datong City; D3 is located 150 m northwest of the Yu River railway bridge; D4 is located $500 \mathrm{~m}$ east of Yanbei
Normal College, to the east of Yu River; D5 is located in Malianzhai Village, Datong City; D6 is located 200 m north of Chenzhuang commune, Datong City; and, D7 is located in Dongfutou Village, Datong City 
The formation and development of GFs in the Datong area were closely related to regional crustal activities. The northwest extension of the basin provides a regional extensional environment for the formation of GFs ( $\mathrm{Li}$ and Yuan 2002; Peng et al. 2017). In addition, it was confirmed by a field "trench" study that JGF was located above the buried active faults and was connected to the buried active faults in the deep part, which manifested the normal fault characteristics of the hanging wall sinking and the foot wall rising (Li and Yuan 2002; Deng 2007). This shows that JGF is a product of tectonic activity and is controlled by active faults. The GFs in the Datong Basin have good continuity on the surface. The JGF and its corresponding secondary GFs are arranged in a geese or plume shape on the plane (Fig. 1), which indicate that the GFs still have the characteristics of twisting activity in the horizontal plane, and this is also the characteristic produced by the geologic structure (Shan et al. unpublished manuscript).

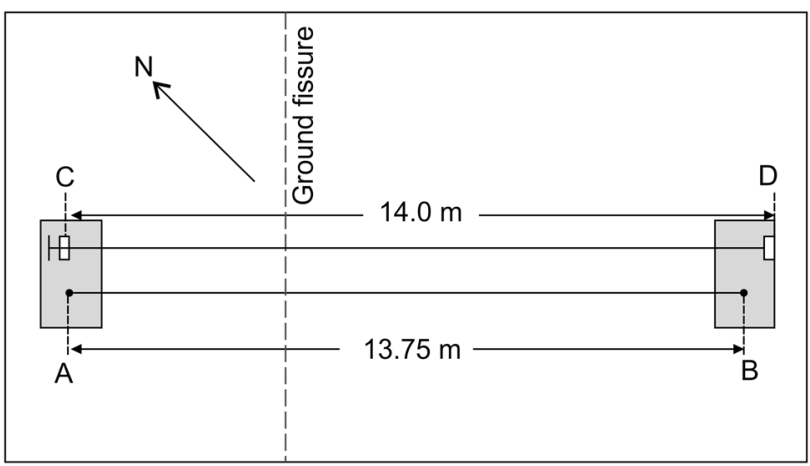

Fig. 3 Schematic of equipment installed at the Jichechang ground fissure monitoring station. AB: location of the DG-1A static level meters device endpoint; $\mathrm{CD}$ : location of the SR-1 horizontal creep meters device endpoint

\section{Data and methods}

\section{Monitoring data acquisition}

A monitoring station was established in the southwest segment of the JGF in 1989 (shown as the black solid rectangle in Fig. 1), which consists of one set of DG-1A static level meters and one set of SR-1 type horizontal creep instruments (Fig. 3). The DG-1A static level meters measure the relative vertical displacement between the two sides of the JGF across the north and south sides of the fissure along a profile with a baseline distance of 13.75 ("AB" in Fig. 3). The SR-1 horizontal creep meters are used to measure the changes in distance between the two sides of the crack running in the horizontal direction with a baseline distance of $14.0 \mathrm{~m}$ ("CD" in Fig. 3). The measurement accuracy of the instrumental set-up is $\pm 0.01 \mathrm{~mm}$.

This monitoring system is installed in a vacant house, and there have been no significant changes in the surrounding local environment; the impact of urban construction on the observational data is considered negligible. For this study, relative vertical and horizontal displacement data for the JGF were obtained for the period between 1998 and 2011 (Fig. 4).

\section{Modeling the effect of water pumping on horizontal aquifer strain}

Pumping can alter the horizontal stress in aquifers, which in turn may influence the activity of the adjacent GFs. Herein, the relationship between the pumping time and the change in the horizontal stress of the aquifer under the condition of fixed distance is analyzed. According to Gervanov's generalized Darcy's law, the average radial velocity $V_{\mathrm{s}}$ of solid
Fig. 4 Time-series displacements of the Jichechang ground fissure. The black line is the vertical differential displacement between the two sides of the crack; the blue line is the horizontal tensional activity

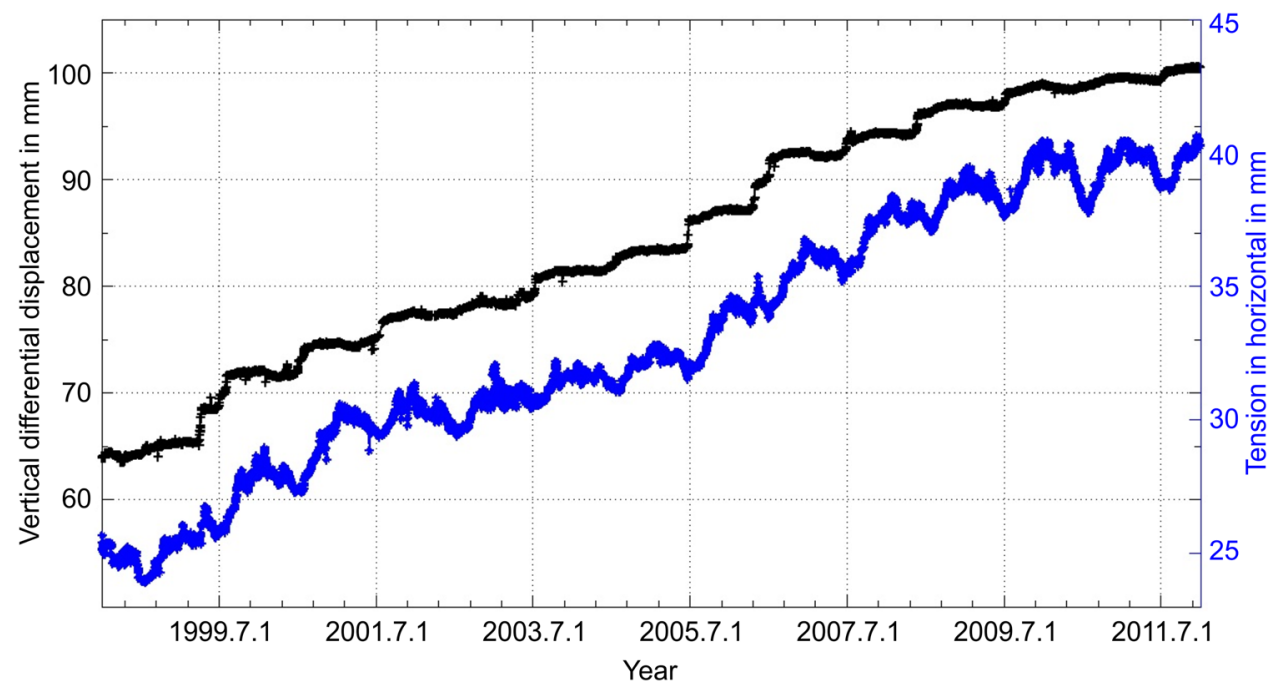


particles in an aquifer can be expressed as follows (Helm 1994a, b; Hsieh and Cooley 1995):

$V_{\mathrm{s}}=q_{\mathrm{b}}-K \frac{\partial h}{\partial r}$,

where $q_{\mathrm{b}}$ is the sum of the porewater flow and aquifer solid particle flow through the radial unit section in unit time (m/day); $K$ is the radial permeability (m/day); $\frac{\partial h}{\partial r}$ is the radial hydraulic gradient; $h$ is the water head; and $r$ is the radial radius.

Due to serious land subsidence in the Datong urban area, the phreatic aquifer has been drained, and thus, most of the drilled areas are confined aquifers below $50 \mathrm{~m}$. Based on the Thiem's equation, assuming a confined aquifer between impermeable water barriers with an infinite radial extension and thickness $b$, and considering the mass continuity equation, a stable pumping rate $Q$ can be written as follows:

$Q=2 \pi r b q_{\mathrm{b}}$

Based on Eq. (1) and (2):

$V_{\mathrm{s}}=\frac{Q}{2 \pi r b}-K \frac{\partial h}{\partial r}$.

The Theis deep descent solution can be expressed as follows (Helm 1994a, b; Hsieh and Cooley 1995):

$h_{0}-h=\frac{Q}{4 \pi r b} \int_{u}^{\infty} \frac{\mathrm{e}^{-x}}{x} \mathrm{~d} x$,

where $u=\frac{r^{2} S_{\mathrm{s}}}{4 K t}, S_{\mathrm{s}}$ is the water storage rate (elastic feedwater, $1 / \mathrm{m}) ; t$ is the continuous stable pumping time calculated from the beginning of pumping; and $h_{0}$ and $h$ are the initial and subsequent hydraulic head, respectively.

The partial derivatives of radial radius $(r)$ on both sides of Eq. (4) are determined as follows:

$\frac{\partial h}{\partial r}=\frac{Q}{2 \pi K r b} \mathrm{e}^{-u}$.

Substituting Eq. (5) into Eq. (3), the radial flow velocity expression for solid particles in a Theis-Theim confined aquifer system during pumping can be obtained as follows:

$V_{\mathrm{s}}=\frac{Q}{2 \pi r b}\left(1-\mathrm{e}^{-u}\right)$.

By integrating time ( $t$ ) with Eq. (6) and assuming that the horizontal displacement of the aquifer is zero at $t=0$, the radial displacement of solid particles at any radial point $(r)$ in an aquifer at any time can be expressed as follows:

$U_{\mathrm{r}}=\int_{0}^{t} V_{\mathrm{s}} \mathrm{d} t+U_{\mathrm{r}}(0)=\frac{Q r S_{\mathrm{s}}}{8 \pi K b}\left[\frac{1-\mathrm{e}^{-u}}{u}+\int_{u}^{\infty} \frac{\mathrm{e}^{-x}}{x} \mathrm{~d} x\right]$.
Thus, the radial strain $\left(\varepsilon_{\mathrm{rr}}\right)$ of an aquifer during pumping can be expressed as follows (Hsieh and Cooley 1995; Wang et al. 2002):

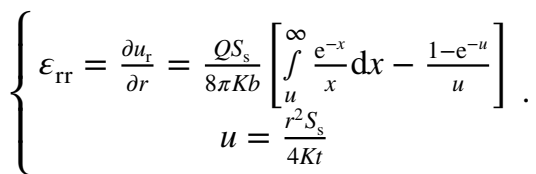

Assuming $r$ is fixed, a dimensionless time function, $t_{d}$, was introduced as follows:

$t_{\mathrm{d}}=\frac{1}{4 u}=\frac{K t}{r^{2} S_{\mathrm{s}}}$.

Thus, $\varepsilon_{\mathrm{rr}}$ in Eq. (1) can be expressed as follows:

$\left\{\begin{array}{c}\varepsilon_{\mathrm{rr}}=\frac{Q S_{\mathrm{s}}}{8 \pi K b}\left[\int_{u\left(t_{\mathrm{d}}\right)}^{\infty} \frac{\mathrm{e}^{-x}}{x} \mathrm{~d} x-\frac{1-\mathrm{e}^{-u\left(t_{\mathrm{d}}\right)}}{u\left(t_{\mathrm{d}}\right)}\right] . \\ u=\frac{r^{2} S_{\mathrm{s}}}{4 K t}\end{array}\right.$

That is, assuming $r$ is fixed, $\varepsilon_{\text {rr }}$ can be expressed as a function of continuous pumping time $t$.

\section{Results and discussion}

\section{JGF activity}

The vertical displacement of the JGF has an overall linear trend but the rates vary significantly over time (Fig. 4). The evidence of stepped activity also indicates that the relative vertical displacement has occurred intermittently. The relative vertical displacement of the JGF is strongest during the spring and summer seasons and weakest in the autumn and winter. The total vertical displacement between the two sides of the crack reached $35 \mathrm{~mm}$ during the observation period with an annual relative displacement rate of approximately $2.5 \mathrm{~mm}$ per year. The activity of the JGF is characterized by a general trend of tensional horizontal movement with periodic compressional movement (Fig. 4). The total tensile displacement was approximately $15 \mathrm{~mm}$ over 14 years, and the annual tensile displacement rate was approximately $1 \mathrm{~mm}$ per year. Overall, vertical displacement was approximately 2.5 times that occurring in the horizontal direction.

\section{Periodicity of the JGF activity}

The monthly average displacement of the JGF based on the observational data is shown in Fig. 5. Datong has a temperate continental monsoon climate with distinct wet and dry periods. The annual rainy season primarily occurs from May to September while precipitation is relatively low from January to April and October to December. The 

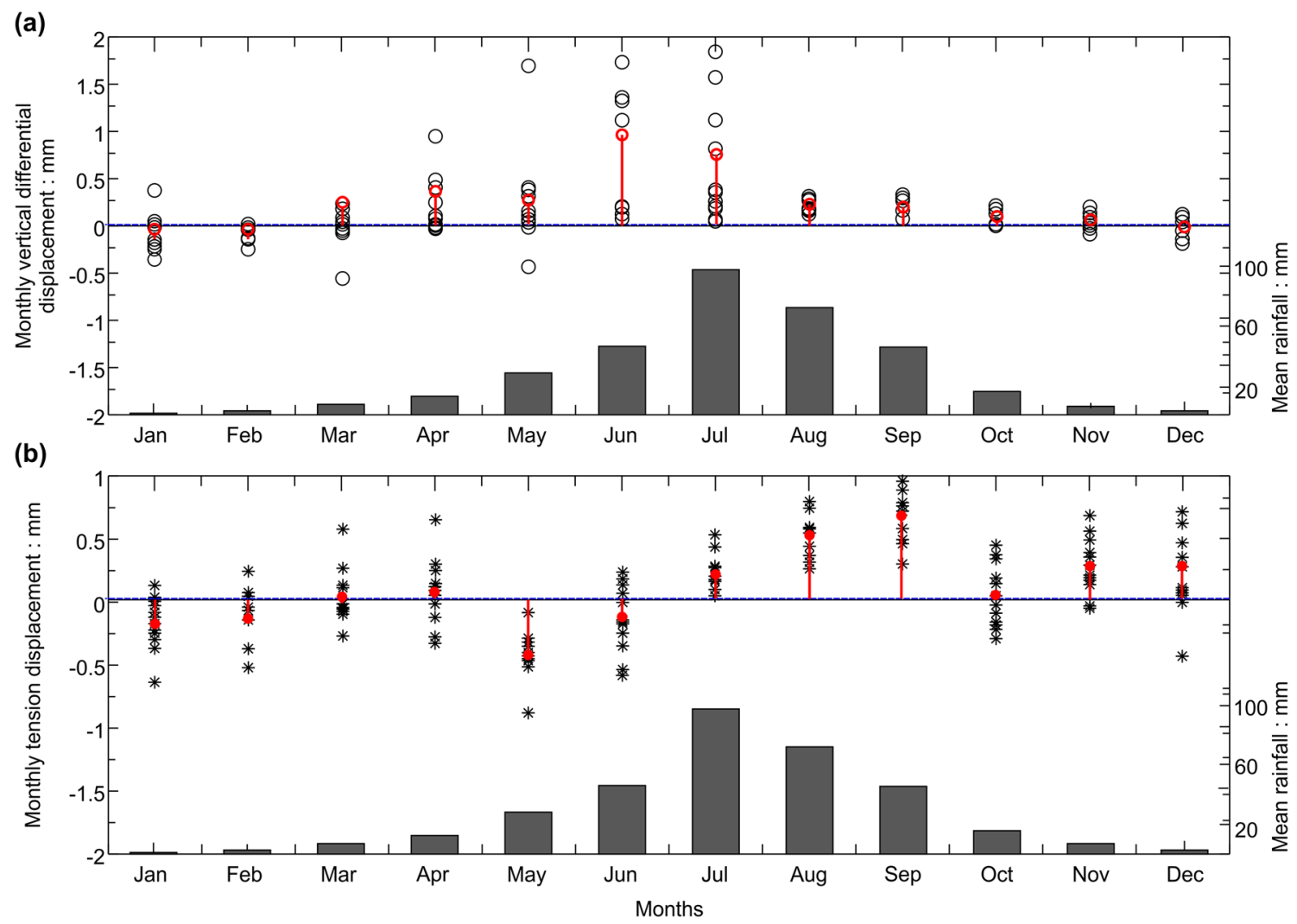

Fig. 5 Monthly average displacement of the Jichechang ground fissure. a Vertical differential displacement between two sides of the JGF; b horizontal tensional activity. Blue lines indicate zero displace- ment. Red-line segments represent the mean displacement for each month. Monthly average rainfall amounts are also shown periodic nature of rainfall is significant, as shown by the monthly average rainfall for 1982-2006 in Fig. 5 (http:// data.cma.cn).

The data show that the tensile displacement in the horizontal direction is high in spring and autumn, particularly in May, August, and September (Fig. 5b), whereas low in June and July when the amount of rainfall is high. Therefore, it is speculated that precipitation is not the main factor affecting the horizontal tensile displacement of the JGF. According to groundwater records (Xing 2018), the second and third quarters are the peak seasons for groundwater exploitation in the Datong Basin. Groundwater is mainly used to irrigate farmland during the peak season, and extraction is concentrated between April and May and between August and September each year (Xing 2018). This pattern of groundwater use is consistent with the horizontal tensile activity of the JGF. According to long-term observational data, the soil on both sides of the JGF extends toward the center of the groundwater funnel during the peak period of groundwater exploitation (Gao 2005); when the peak period of groundwater exploitation ends, horizontal tensile activity decreases or stops altogether (Gao 2005; Yang et al. 2014). These observations are consistent with our findings, which indicate that the extraction of groundwater is closely linked to the horizontal tensile behavior of the JGF.

As shown in Fig. 5a, the vertical differential displacement between the two sides of the JGF is large during June and July, with June being the most active time. As such, maximum vertical differential displacement does not coincide with the period of maximum average rainfall (i.e., July). Furthermore, vertical differential displacement is small in August and September when high amounts of precipitation occur. This indicates that precipitation is not the main factor controlling the vertical differential displacement of the JGF. This is further supported by considering the relevant statistics for the year 2004, a particularly dry year, wherein the average monthly rainfall was below $10 \mathrm{~mm}$, which is less than $1 / 8^{\text {th }}$ of the average monthly rainfall in Datong over the previous 10 years (Fig. 6). Despite this, vertical differential displacement was not significantly lower in 2004. Given that maximum vertical differential displacement occurs after agricultural irrigation in April and May, large-scale groundwater extraction in the basin is likely a contributing factor to the activity of the JGF alongside precipitation. In contrast to annually fluctuating precipitation, the agricultural irrigation period is regular and fixed each year, which 
Fig. 6 Jichechang ground fissure activity and rainfall between 2001 and 2006. a, b As for Fig. 3; c rainfall for the period 2001-2006. Gray shading in a represent two-step accelerations in the vertical direction within a short period of time. The vertical blue line in a represents the date of the Wen'an Earthquake (a)

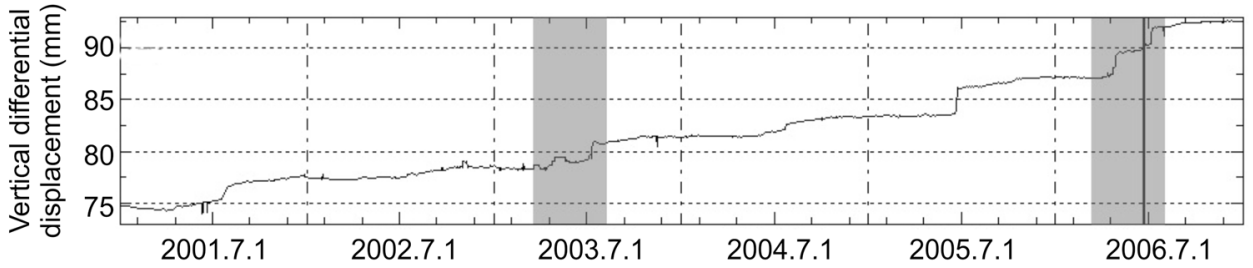

(b)

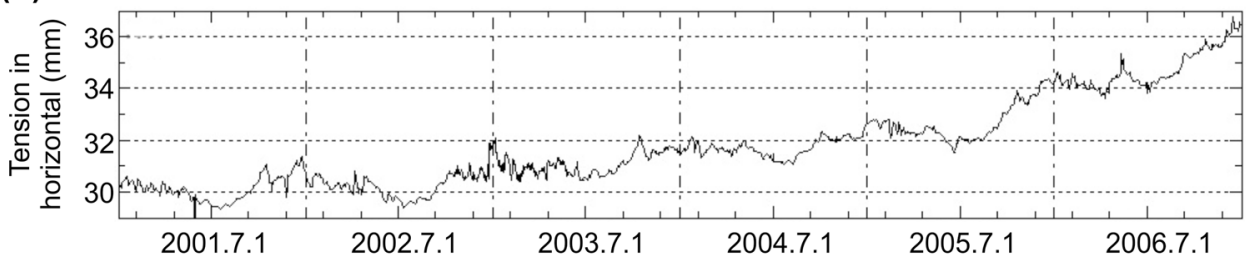

(c)

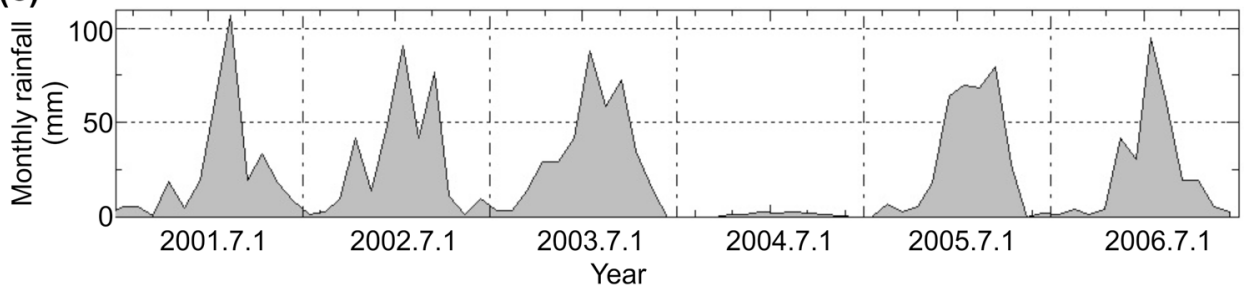

closely corresponds to the pattern of vertical displacement activity in the JGF.

\section{Step-like vertical displacement}

The vertical activity of the JGF exhibits quasi-periodic step-like displacement acceleration characteristics. Some step-like acceleration events occur in a single jump, whereas others show two jumps within a short period (indicated by the gray shading in Fig. 6a in 2003 and 2006). According to the observational data, the step displacement acceleration events occur approximately every 320-420 days (Fig. 7a) and last for 18-38 days (Fig. 7b). The entire displacement acceleration during these periods is between $\sim 1.0 \mathrm{~mm}$ (a)

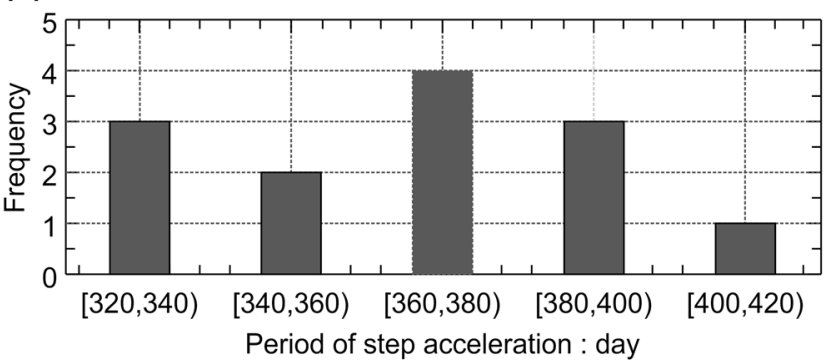

(c)

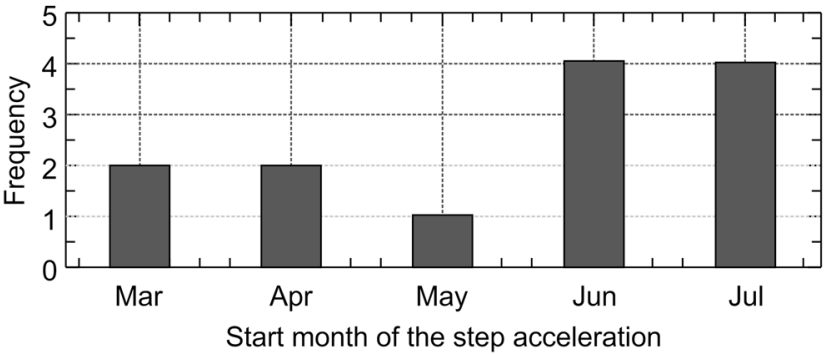

(b)

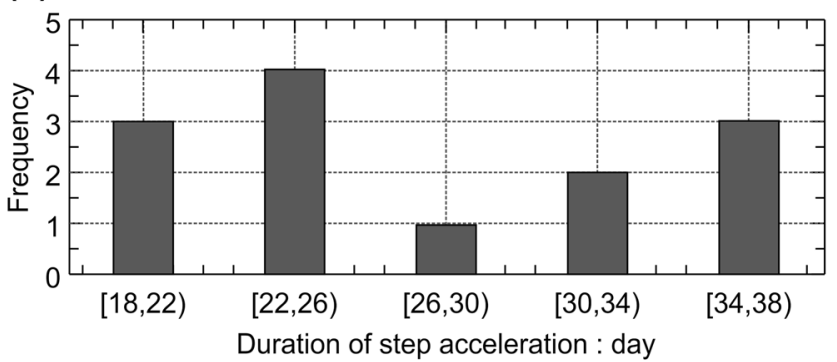

(d)

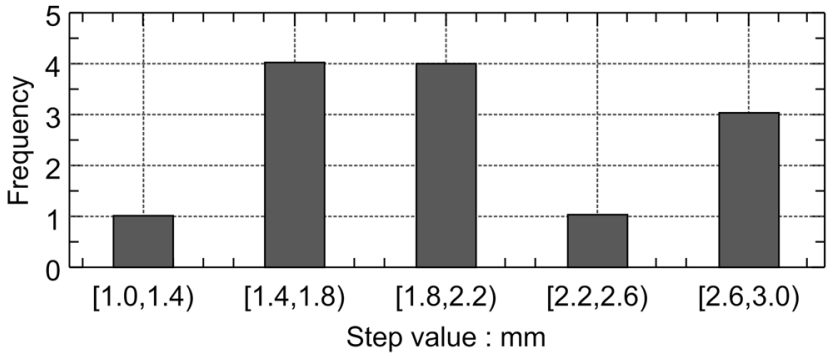

Fig. 7 Frequency data for vertical step displacements recorded at the Jichechang ground fissure. a Cyclicity; b duration; c seasonality; and d magnitude 
and $3.0 \mathrm{~mm}$ (Fig. 7d) with an average of approximately $2.0 \mathrm{~mm}$. These stepped events account for approximately $63 \%$ of the annual JGF vertical differential displacement observed during the observation period.

In the northern Cascadia subduction zone in North America, repeated slow slip events at the deep interface have been used as a real-time indicator of stress loading in the Cascadia megathrust earthquake zone, including step displacement (Rogers and Dragert 2003). For the JGF, all step-like acceleration events occurred between March and July with $60 \%$ occurring in June and July (Fig. 7c). Considering that the timing of these acceleration events coincided with the periods of intensive local irrigation, it is speculated that the two are related. Moreover, increases in precipitation may have a positive effect on the occurrence of step-like displacement events.

According to GF drilling work (Liu and Chen 1995; Li and Yuan 2002; Deng 2007), the JGF is connected at depth with the concealed Fangzicun Fault ("FZC" in Fig. 1), and the tectonic stress placed on the JGF is transmitted from the activity of this fault. When the tectonic stress transfers upward, it is hindered by the overlying soil layer resulting in stress accumulation. When the GF or the underlying fault is located within the radial tensile strain zone created by groundwater pumping, the normal stress on the fault plane (i.e., the friction resistance on the section) would be reduced. Under the combined action of tectonic stress and gravity, the activity of the GF is accelerated and the vertical step-like displacement characteristic of the JGF is formed.

\section{Seismicity impacts}

Several studies have shown that the occurrence of GFs is related to seismic activity (Dou et al. 2005; Tuttle et al. 2011; Yang et al. 2012; Guo and Wang 2017). After the Tangshan Earthquake struck northeastern China in 1976, the effect of local seismicity on GF activity has been studied for earthquake prediction (Zhao 1991; Li 2004; Wang et al. 2004; Liu 2008). Because the JGF monitoring data provide a continuous record, it provides an ideal data source to study the correlation between GF activity and seismicity. For example, research has been done to analyze the relationships between abnormal displacements of the JGF and the surrounding earthquakes (Table 1) (Zhang et al. 2013; Li 2015). This work indicates that anomalies in JGF activity can occur 1 month to 4 years before an earthquake, assuming that the magnitude of the earthquake is $>5.0$ and the distance between the epicenter and the GF is $<300 \mathrm{~km}$ (Zhang et al. 2013; Li 2015). However, the relationship between earthquakes and fissure displacement anomalies is very complicated; the occurrence of an abnormal displacement before the earthquake is not necessarily related to the earthquake. It is not appropriate, therefore, to "look for" anomalous displacements after an earthquake and infer that they are precursory indicators that can be used for earthquake prediction.

Under the assumption that the magnitude and timing of abnormal displacement are proportional to the magnitude of an earthquake and inversely proportional to its epicentral distance, Fig. 8a, b plot these variables for the JGF. The results show that there is no significant correlation between them.

Furthermore, the definition of abnormal displacement is not clear. For example, the abnormal displacement of the JGF in the horizontal and vertical directions that occurred before the Wen'an Earthquake (July 4, 2006, Table 2) was not significant (Fig. 6). Although high-frequency displacements were observed, such a signal is ubiquitous in the monitoring record. Therefore, a high-frequency displacement signal cannot be considered indicative of an earthquake. Moreover, step displacements in the vertical direction have also occurred in earthquake-free years.

Table 1 Abnormal displacements of the JGF and the surrounding earthquakes (data from Zhang et al. 2013 and Li 2015)

\begin{tabular}{|c|c|c|c|c|c|c|}
\hline No & Earthquake date & $\begin{array}{l}\text { Earthquake } \\
\text { magnitude } \\
(M)\end{array}$ & $\begin{array}{l}\text { Distance between the } \\
\text { station and the epicenter } \\
(\mathrm{km})\end{array}$ & $\begin{array}{l}\text { Abnormal direction } \\
(\mathrm{V}=\text { vertical, } \mathrm{H}=\text { hori- } \\
\text { zontal })\end{array}$ & $\begin{array}{l}\text { Maximum } \\
\text { displacement } \\
(\mathrm{mm})\end{array}$ & $\begin{array}{l}\text { Time interval between the } \\
\text { anomaly and the earthquake } \\
\text { (days) }\end{array}$ \\
\hline \multirow[t]{2}{*}{1} & 03-26-1991 & 5.8 & 53 & V & 7.129 & 548 \\
\hline & & & & $\mathrm{H}$ & 2.091 & 548 \\
\hline 2 & 05-03-1996 & 6.4 & 300 & V & 5.360 & 10 \\
\hline \multirow[t]{2}{*}{3} & 01-10-1998 & 6.2 & 127 & V & 5.393 & 270 \\
\hline & & & & $\mathrm{H}$ & 0.718 & 182 \\
\hline 4 & 03-11-1999 & 5.6 & 172 & $\mathrm{H}$ & 1.038 & 241 \\
\hline \multirow[t]{2}{*}{5} & 11-01-1999 & 5.6 & 53 & V & 6.621 & 212 \\
\hline & & & & $\mathrm{H}$ & 1.038 & 30 \\
\hline \multirow[t]{2}{*}{6} & 07-04-2006 & 5.1 & 290 & $\mathrm{~V}$ & 8.551 & 80 \\
\hline & & & & $\mathrm{H}$ & 0.235 & 75 \\
\hline
\end{tabular}


Fig. 8 Correlation between the abnormal displacement in the Jichechang ground fissure and surrounding earthquakes. a Abnormal displacement and earthquake magnitude: distance ratio; b deformation time interval and earthquake epicentral distance (a)

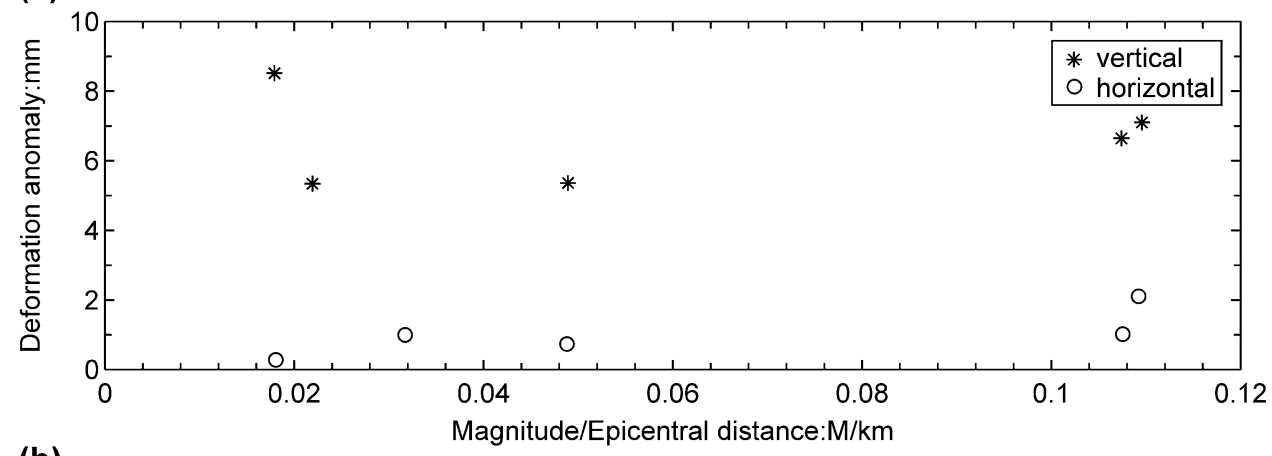

(b)

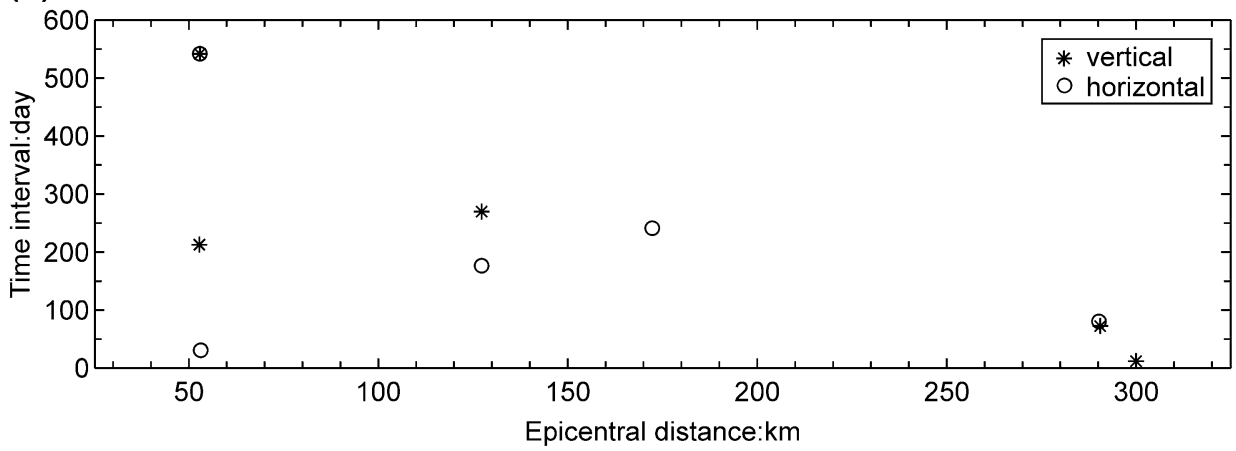

Groundwater drawdown and fissure distribution

Table 2 Relationship between $t$ and $r$ at tensile strain maxima

\begin{tabular}{llrr}
\hline$r(\mathrm{~m})$ & $\begin{array}{l}T(\mathrm{~h}=\text { hours, } \min =\min - \\
\text { utes, } \mathrm{d}=\text { days })\end{array}$ & $r(\mathrm{~m})$ & $t$ (days) \\
\hline 100 & $14.3 \mathrm{~min}$ & 2500 & 6.2 \\
200 & $57.3 \mathrm{~min}$ & 3000 & 9.0 \\
500 & $6.0 \mathrm{~h}$ & 4000 & 15.9 \\
750 & $13.4 \mathrm{~h}$ & 5000 & 24.9 \\
1000 & $23.9 \mathrm{~h}$ & 6000 & 35.8 \\
1250 & 1.6 days & 7500 & 56.0 \\
1500 & 2.2 days & 10,000 & 100.0 \\
1750 & 3.0 days & 12,500 & 155.5 \\
2000 & 4.0 days & 15,000 & 224.0 \\
\hline
\end{tabular}

Finally, due to the inhomogeneity of the crust, the evolution of crustal deformations before an earthquake typically has four stages: (1) long-term creep; (2) accelerated creep; (3) coseismic rupture; and (4) post-earthquake adjustment. Therefore, whether short-term anomalies are accompanied by medium-term and long-term crustal deformation anomalies is an important criterion to judge the reliability of a single anomaly observation (State Seismological Bureau 1998). Importantly, the JGF observation data are affected by many non-tectonic factors including water pumping, and their influence must be accounted for in the study of earthquake precursory information.
As is typical for inland cities in China, the water used for domestic, industrial, and agricultural purposes in Datong is mainly derived from groundwater. The persistent exploitation of groundwater in the city has led to a continuous decline in the shallow-middle water table and large-scale funnel-shaped drop in the groundwater level over a total area of $130 \mathrm{~km}^{2}$ (Fig. 1; Zhang 2017). The GFs in Datong are distributed not only in the areas of intense groundwater exploitation, but also where groundwater exploitation is limited. Importantly, this indicates that groundwater exploitation is not the factor affecting the GFs in Datong; rather, the activity of concealed faults is considered the key factor affecting the occurrence of GFs. Moreover, previous studies have shown that the maximum land-subsidence rate in Datong is approximately $15 \mathrm{~mm}$ per year (Yang et al. 2014, 2019). Compared to other cities in China with higher landsubsidence rates and no GFs, such as Shanghai, Tianjin, and Changzhou (Zhang et al. 2016; Dong et al. 2018), the landsubsidence rate in Datong is not considered large enough to generate GFs.

\section{Effect of water pumping on JGF activity}

Based on the discussion in Sect. 3.2, Wang et al. (2002, 2003) calculated the variation characteristics of radial strain with groundwater pumping time, as shown in Table 3 . 
Table 3 Variations in radial strain with groundwater pumping time

\begin{tabular}{ll}
\hline Pumping time $t$ & Radial strain characteristics (fixed $r$ ) \\
\hline $0<t<0.1991 \frac{S_{s} r^{2}}{K}$ & Radial tensioning stage: tensile strain increases with time \\
$t=0.1991 \frac{S_{\mathrm{s}} r^{2}}{K}$ & Tensile strain reaches its maximum: $\varepsilon_{\mathrm{rr}}(\mathrm{max})=-0.4245 \frac{Q S_{\mathrm{s}}}{8 \pi K b}$ \\
$0.1991 \frac{S_{\mathrm{s}} r^{2}}{K}<t<0.7776 \frac{S_{\mathrm{s}} r^{2}}{K}$ & Radial tensioning stage: tensile strain decreases as time increases \\
$t=0.7776 \frac{S_{\mathrm{s}} r^{2}}{K}$ & No radial tensile strain state: $\varepsilon_{\mathrm{rr}}=0$ \\
$t>0.7776 \frac{S_{\mathrm{s}} r^{2}}{K}$ & Radial extrusion stage: extrusion strain gradually increases with time \\
\hline
\end{tabular}

The Mohr-Coulomb law shows that the shearing resistance of soil is related to the normal stress on the shear plane, which increases with an increase in normal stress. According to Table 3 , the radial tensile stress caused by groundwater pumping is in an increasing stage when $0<t<0.1991 \frac{S_{\mathrm{s}} r^{2}}{K}$. Under this condition, the normal stress acting on the fracture surface gradually decreases, the strength of the shearing resistance acting on the fault plane is continuously reduced, and the fault activity is accelerated. When $t=0.1991 \frac{S_{\mathrm{s}}{ }^{2}}{K}$, the radial tensile stress caused by continuous groundwater pumping reaches its maximum, and the normal stress and shearing resistance of the fault plane decrease to their minimum values. When $t>0.1991 \frac{S_{\mathrm{s}} r^{2}}{K}$, the radial tensile stress starts to decrease with an increase in the pumping time, the normal stress and shearing resistance of the fault plane continuously increase, and the acceleration activity of the fault or GF is reduced or stopped. Therefore, the acceleration effect of pumping on GF activity mainly occurs when $0<t<0.1991 \frac{S_{\mathrm{s}} r^{2}}{K}$.

Based on previous studies (Liu and Chen 1995; Wang et al. 2002), calculations for the GF were performed based on the following assumptions: aquifer water-storage rate $S_{\mathrm{s}}=5.0 \times 10^{-5} / \mathrm{m}$; aquifer permeability coefficient $\mathrm{K}=10 \mathrm{~m} /$ day; thickness of the aquifer $\mathrm{b}=20 \mathrm{~m}$; and when the unit pumping rate $Q=1 \mathrm{~m}^{3} /$ day, the maximum tensile strain is $4.22 \times 10^{-9}$. When $Q, S_{\mathrm{s}}, K$, and $b$ are fixed, as long as the continuous and steady pumping time $(t)$ reaches $0.1991 \frac{S_{\mathrm{s}} r^{2}}{K}$, the maximum tensile strain generated by pumping is the same and is independent of the distance between the wells and the GF.

Above $t=0.1991 \frac{S_{\mathrm{s}} r^{2}}{K}$, the continuous and steady pumping time $(t)$ required to reach the maximum tensile strain is proportional to the distance $(r)$ between the pumping well and the GF. Using these values, Table 2 shows the respective values of $t$ and $r$ required to reach the maximum tensile strain: when $r$ is less than $1000 \mathrm{~m}$, the acceleration effect of pumping on GF activity is maximized within less than a day for the given parameter values; when $r$ is less than $2500 \mathrm{~m}$, the tensile strain reaches its maximum $t$ within 1 week; when $r$ is less than $6000 \mathrm{~m}$, the tensile strain reaches its maximum $t$ within 1 month; and when $r$ is greater than $10,000 \mathrm{~m}$, more than 3 months of continuous stable pumping are needed to reach the maximum tensile strain. The peak periods of agricultural irrigation in the Datong area are April-May and August-September. As such, it is difficult to pump continuously for more than 3 months. Therefore, water pumping more than $10 \mathrm{~km}$ away has a weaker acceleration effect on the GF activity. This is consistent with the results of large-scale pumping tests in this area (Che and Yu 2004). The deformation acceleration of the JGF lasts for 18-38 days and mainly occurs in June and July (Fig. 7b, c). Thus, considering that the continuous pumping time of a single agricultural well does not generally exceed 7 days, it is speculated that the vertical activity of the JGF is mainly the result of water pumping within a $10-\mathrm{km}$ radius.

\section{Possible formation mechanism of the JGF}

The formation mechanisms of GFs are diverse, mainly including tectonic activities, groundwater exploitation, stratum lithology conditions, geomorphological boundaries, precipitation, surface water infiltration, underground mining, building load and dynamic loads (Peng et al. 2017). The formation and development of GFs in locomotive factories are restricted by many factors, and their formation mechanism is complicated. Neotectonic activity is the controlling factor for the formation of GFs in the locomotive factory. Under the influence of upper mantle uplift, regional tensile stress, and fault block movement, a buried fracture system was formed on the hanging wall along the Kouquan Fault, laying foundation for the formation of GFs (Wang et al. 2020). Moreover, the intense groundwater exploitation in the urban area of Datong, especially the seasonal exploitation of group wells, plays a decisive role in the magnitude of GF activity. The field observations showed that the rates of horizontal expansion and vertical displacement of GFs in the locomotive factory are $1 \mathrm{~mm}$ and $2.5 \mathrm{~mm}$ per year, respectively. However, evidence from the study of geology, earthquakes, and geodesy indicate that the rate of current horizontal expansion of the Shanxi graben system is $0-0.5 \mathrm{~mm} /$ year where the Datong Basin is located. The vertical slip rate of the normal fault of the Datong Basin varies from 0.12 to $1.48 \mathrm{~mm} /$ year (Zhang et al. 1998; Deng et al. 2002; Wang and Shen 2020). Therefore, it is inappropriate to regard the rate of GF activity as the amount of deformation caused by structural factors. Hence, it is reasonable to infer that $30-40 \%$ of the 
field observations of GF activity is a result of the tectonic activity, after eliminating the displacement activity caused by the seasonal pumping of the group of wells. The rate of horizontal expansion is $0.3-0.4 \mathrm{~mm} /$ year, and the rate of vertical displacement is $0.75-1.0 \mathrm{~mm} /$ year, all of them within the range of regional tectonic activity rate.

\section{Conclusions}

Datong is severely affected by GF disasters. In this study, monitoring data were used to study the most active fissure in Datong (the JGF) to characterize its activity and controlling mechanisms. The main conclusions of the research are as follows:

- The vertical differential displacement feature of the JGF is significant, and the magnitude of this activity is approximately 2.5 times higher than horizontal tension displacement.

- GF activity is highly seasonal, and periodic agricultural irrigation is considered the driving factor; the activity of the JGF is significantly enhanced during the agricultural irrigation season, and rainfall has less impact on seasonal activity.

- The JGF experiences a period of stepped displacement acceleration every 320-420 days lasting for 18-38 days and with an average displacement of approximately $2.0 \mathrm{~mm}$. These stepped displacements account for approximately $63 \%$ of the annual vertical differential displacement recorded in this fissure.

- The effect of seismicity on the activity of GFs is very complicated. The abnormal displacement that tends to occur before an earthquake is not necessarily causative; it is not appropriate to use GF activity as precursory information in earthquake prediction without eliminating the influence of other non-tectonic factors.

- Water pumping within a $10-\mathrm{km}$ radius has a positive effect on GF activity. Based on numerical simulations, when the distance between the pumping wells and a GF is less than $1000 \mathrm{~m}$, the acceleration effect on GF activity can be maximized within less than 1 day.

Further research is required to obtain groundwater monitoring data near the JGF to analyze the correlation between groundwater fluctuations and GF activity. Additionally, detailed records of agricultural activity in the Datong area could contribute to further in-depth analysis of the relationships between irrigation practices and GF activity.

Acknowledgements We thank Editor-in-Chief Gunter Dörhöfer, Associate Editor Gioacchino Francesco Andriani, E. Dindi Ndubi and two other anonymous reviewers for their help with improving and clarifying the manuscript. We thank Engineer Hui Chen for the help in drawing the pictures.

Author contributions RL performed data processing and modeling and drafted the manuscript; CY revised the manuscript and analyzed the results; QW and LJ contributed to interpretation.

Funding This research was jointly funded by the National Natural Science Foundation of China (NSFC) (no. 41731066), China Geological Disaster Investigation Project (no. DD20190637), State Key Project of Research and Development Plan (no. 2018YFC1504805), Fundamental Research Funds for the Central Universities (CHD) (no. 300102269204), Shaanxi Provincial Natural Science Basic Research Project (no. 2019JM-245), Science and Technology Research and Development Program of Shanxi Province (no. 20140313023-1), and Basic Research Project of the Institute of Earthquake Science, CEA (no. 2017IES0101).

Availability of data and material The datasets generated during and/or analyzed during the current study are available from the corresponding author on reasonable request.

Code availability Not applicable.

\section{Declarations}

Conflict of interest The authors declare that they have no conflict of interest.

Open Access This article is licensed under a Creative Commons Attribution 4.0 International License, which permits use, sharing, adaptation, distribution and reproduction in any medium or format, as long as you give appropriate credit to the original author(s) and the source, provide a link to the Creative Commons licence, and indicate if changes were made. The images or other third party material in this article are included in the article's Creative Commons licence, unless indicated otherwise in a credit line to the material. If material is not included in the article's Creative Commons licence and your intended use is not permitted by statutory regulation or exceeds the permitted use, you will need to obtain permission directly from the copyright holder. To view a copy of this licence, visit http://creativecommons.org/licenses/by/4.0/.

\section{References}

Bankher KA, Al-Harthi AA (1999) Earth fissuring and land subsidence in western Saudi Arabia. Nat Hazards 20:21-42

Brunori CA, Bignami C, Albano M, Zucca F, Samsonov S, Groppelli G, Norini G, Saroli M, Stramondo S (2015) Land subsidence, ground fissures and buried faults: InSAR monitoring of Ciudad Guzman (Jalisco, Mexico). Remote Sens 7:8610-8630

Cen M (2015) Cenozoic tectonic evolution of Datong Basin in the northeastern margin of Ordos Basin. Hefei University of Technology

Che YT, Yu JZ (2004) Investigation and study of typical anomalies of underground fluid. China Meteorological Press, Beijing

Chen ZX, Ye WJ (2002) Simulation study on the active tectonics and displacement in Datong city. J xi' an Eng Univ 4:38-40

Deng A (2007) Discussion of the genesis, distribution characteristics and control measures of the ground fissures in Datong City. Saf Environ Eng 14:44-48 
Deng QD, Yu GH, Ye WH (1992) Study on the relationship between surface rupture parameters and earthquake magnitude, active fracture study. Seismological Press, Beijing

Deng QD, Zhang PZ, Ran YK, Yang XP, Min W, Chu QZ (2002) The basic characteristics of active tectonics in China. Sci China (ser D) 32:1020-1030

Dong SC, Samsonov S, Yin HW, Huang LL (2018) Two-dimensional ground deformation monitoring in Shanghai based on SBAS and MSBAS InSAR methods. J Earth Sci 29:960-968

Dong SG, Tang ZH, Liu BW, Su CL (2008) The numerical simulation of groundwater and evaluation of optimal allocation of water resources in Datong basin. Geotech Investig Surv 3:30-35

Dou AX, Wang XQ, Ding X, Wang DL (2005) Extraction of ground fissures caused by earthquake MS6.8 in Bachu-Jiashi area. In: IEEE 2005 international geoscience and remote sensing symposium, Seoul, July 25-29, pp 5053-5055

Fan JM (2003) The study on the environmental \& geographic problems and counter measures against over-tapping of city ground water of Datong. Groundwater 25:19-20

Fergason KC, Rucker ML, Panda BB (2015) Methods for monitoring land subsidence and earth fissures in the Western USA. Proc Int Assess Hydrol Sci 372:361-366

Gao W (2005) Actuality and influence evaluate for the ground fissure in power plant. Electr Power Surv Des 01:26-29

Geng DY, Zhong SL (2000) Ground fissure hazards in USA and China. Acta Seismol Sin 13:466-476

Guo H, Wang X (2017) Relationship between the present-day ground fissure in Hebei, Longyao and the 1966 Xingtai earthquake. North China Earthq Sci 35:10-16

Guo HM, Wang YX, Wang RF, Deng AL (2002) Shallow groundwater environment evolution impacted by intensive anthropic activities in Datong city. Geol Sci Technol Inf 21:65-72

Han Y (2008) Characters of the groundwater flow field and hydrochemistry field in Datong Basin. Geol Surv Res 31:138-146

Han Y, Zhang HM, Zhang YF, Zhang X (2017) Distribution regularity, origin and quality division of high arsenic, fluorine and iodine contents in groundwater in Datong Basin. Geol Surv China 4:57-68

Helm DC (1994a) Horizontal aquifer movement in a Theis-Thiem confined system. Water Resour Res 30:953-964

Helm DC (1994b) Hydraulic forces that play a role in generating fissures at depth. Bull Ass Eng Geol 31:293-304

Holzer TL (1984) Ground failure induced by ground-water withdrawal from unconsolidated sediments. Geol Soc Am Rev Eng Geol 6:67-105

Holzer TL (1991) Earth fissures and localized differential subsidence. Water Res 17:223-227

Howard KWF, Zhou W (2019) Overview of ground fissure research in China. Environ Earth Sci 78:97

Hsieh PA, Cooley RL (1995) Comment on "horizontal aquifer movement in a Theis-Theim confined system" by Donald C. Helm Water Resour Res 31:3107-3111

Jachens RC, Holzer TL (1982) Differential compaction mechanism for earth fissures near Casa Grande, Arizona. Geol Soc Am Bull 93:998-1012

Li SD, Yuan RM (2002) The formation mechanism of ground fissure in Datong city. Acta Scientiarum Naturalium Universitatis Pekinensis 38:104-108

Li XY (2015) Relationship of leveling deformation anomalies of ground fissure in Datong Tongche company with moderately strong earthquakes in juncture area of Shanxi, Hebei and Inner Mongolia. Earthq Res Shanxi 162:16-20

Li Z (2004) The cause of tectonic ground fissures and the seismic exploration. Coal Geol Explor 32:54-56

Liu K (2008) The correlation analysis of earthquakes and ground fissures activity in Hebei plain. North China Earthq Sci 26:45-50
Liu NN, Lu QZ, Li J, Peng JB, Fan W, Liu WL (2019a) Physical modeling and numerical simulation of the seismic responses of metro tunnel near active ground fissures. Complexity 2019:9014641

Liu NN, Feng XY, Huang QB, Fan W, Peng JB, Lu QZ, Liu WL (2019b) Dynamic characteristics of a ground fissure site. Eng Geol 248:220-229

Liu YH, Chen ZX (1995) Study on urban geology of Datong. Xi'an Map Publishing House, Xi'an

Liu YH, Cheng ZX, Niu FJ (1999) Characteristics of land subsidence and environmental geology effects induced by groundwater exploration in Datong City. Chin J Geol Hazard Control 9:155-160

Lu QZ, Liu Y, Peng JB, Li L, Fan W, Liu NN, Sun K, Liu RD (2020) Immersion test of loess in ground fissures in Shuanghuaishu, Shaanxi Province, China. Bull Eng Geol Environ 79:2299-2312

Lu QZ, Zhao FK, Peng JB, Bo F (2013) Overview on rupture propagation studies of buried ground fissures. J Eng Geol 21:898-907

Pacheco-Martínez J, Hernandez-Marín M, Burbey TJ, González-Cervantes N, Ortíz-Lozano JA, Zermeño-De-Leon ME, Solís-Pinto A (2013) Land subsidence and ground failure associated to groundwater exploitation in the Aguascalientes Valley, México. Eng Geol 164:172-186

Peng JB (2012) Xi' an ground fissures hazards. Science Press, Beijing

Peng JB, Chen LW, Huang QB, Men YM, Fan W, Yan JK (2013) Physical simulation of ground fissures triggered by underground fault activity. Eng Geol 155:19-30

Peng JB, Lu QZ, Huang QB (2017) Ground fissure disaster in Fenwei basin. Science Press, Beijing

Peng JB, Meng LC, Lu QZ, Deng YH, Meng ZJ (2018) Development characteristics and mechanisms of the Taigu-Qixian earth fissure group in the Taiyuan basin. China Environ Earth Sci 77:407

Ren JG, Gong WG, Jiao XJ (2004) Distribution characteristics of ground fissure in Datong and its development trend. Earthq Res Shanxi 118:39-42

Rogers G, Dragert H (2003) Episodic tremor and slip on the Cascadia subduction zone: The chatter of silent slip. Science 300:1942-1943

Shanxi Earthquake Agency (2005) The Datong-Yanggao earthquake of Shanxi Province. Seismological Press, Beijing

State Seismological Bureau (1998) Crustal deformation analysis and prediction method. Seismological Press, Beijing

Tuttle M, Law KT, Seeber L, Jacob K (2011) Liquefaction and ground failure induced by the 1988 Saguenay, Quebec, earthquake. Can Geotech J 27:580-589

Wang GY, You G, Shi B, Yu J, Li HY, Zong KH (2009) Earth fissures triggered by groundwater withdrawal and coupled by geological structures in Jiangsu Province, China. Environ Geol 57:1047-1054

Wang GY, You G, Zhu JQ, Yu J, Li W (2016) Earth fissures in SuXi-Chang Region, Jiangsu, China. Surv Geophys 37:1095-1116

Wang JM (2000) Theory of ground fissures hazards and its application. Science and Technology Press of Shaanxi, Xi'an

Wang M, Shen Z-K (2020) Present-day crustal deformation of continental China derived from GPS and its tectonic implications. J Geophys Res Solid Earth. https://doi.org/10.1029/2019JB018774

Wang JM, Wang CM, Liu K (2001) Progress in ground fissures and its hazard research. Adv Earth Sci 16:303-313

Wang QL, Liu YH, Chen ZX, Wang WP (2002) Horizontal strain of aquifer induced by groundwater pumping - a new mechanism for ground fissure movement. J Eng Geol 10:46-50

Wang QL, Ran XL, Guo JZ (2003) Horizontal aquifer movement caused by fixed-drop pumping of ground water from Theis-Thiem confined system. J Geodesy Geodyn 23:12-16

Wang XW, Guo XQ, Chen JG (2004) Study on the relationship of the fixed leveling anomalies in Datong Seismostation with earthquakes. North China Earthq Sci 22:18-22 
Wang FY, Peng JB, Chen ZX, Wang QL, Meng ZJ, Qiao JW, Zhao JY (2020) Development characteristics and mechanisms of damagecausing urban ground fissures in Datong City. China. Eng Geol 271(3-4):105605

Xie XS, Jiang WL, Wang R, Wang HZ, Feng XY (2003) Holocene paleo-seismic activities on the Kouquan fault zone, Datong basin, Shanxi province. Seismol Geol 25:359-374

Xing DX (2018) Study on dynamic change characteristics and treatment measures of groundwater overdraft area in Datong city. Groundwater 40:65-67

Xu W, Liu XD, Zhang SM (2011) Research of recent late Quaternary activity in the middle part of Kouquan fault. Earthq Res China 27:386-395

Yang CS, Lu Z, Zhang Q, Liu RC, Ji LY, Zhao CY (2019) Ground deformation and fissure activity in Datong Basin, China 20072010 revealed by multi-track InSAR. Geomat Nat Hazards Risk 10:465-482

Yang CS, Lu Z, Zhang Q, Zhao CY, Peng JB, Ji LY (2018) Deformation at Longyao ground fissure and its surroundings, North China plain, revealed by ALOS PALSAR PS-InSAR. Int J Appl Earth Observ Geoinform 67:1-9

Yang CS, Zhang Q, Zhao CY, Ji LY (2014) Monitoring land subsidence and fault deformation using the small baseline subset InSAR technique: a case study in the Datong Basin, China. J Geodyn 75:34-40

Yang FH, Liu WJ, Yang XL (2012) Case study of ground fissures generated by liquefaction following the Wenchuan earthquake. Adv Mat Res 446-449:12-15
Ye S, Franceschini A, Zhang Y, Janna C, Gong X, Yu J, Teatini P (2018) A novel approach to model earth fissure caused by extensive aquifer exploitation and its application to the Wuxi Case, China. Water Resour Res 54:2249-2269

Zan YL (2006) Relation between ground fissure formation and groundwater mining in urban Datong. Coal Geol China 18:26-29

Zhang DK, Liu HL, Deng HY (2013) Deformation level observation for ground fissures at Datong Tong Train Co. and its earthquake reflecting ability. Earthq Res Shanxi 155:23-27

Zhang JC (2017) Linear prediction analysis of groundwater level recovering in groundwater over-exploitation area of Datong City. Groundwater 39:65-66

Zhang YH, Wu HA, Kang YH, Zhu CG (2016) Ground subsidence in the Beijing-Tianjin-Hebei region from 1992 to 2014 revealed by multiple SAR stacks. Remote Sens 8:675

Zhang YQ, Mercier JL, Vergely P (1998) Extension in the graben systems around the Ordos (China), and its contribution to the extrusion tectonics of south China with respect to Gobi-Mongolia. Tectonophysics 285:41-75

Zhao XC (1991) Fissures and its characteristics of Heze earthquake M7.0 in 1937. Crustal Deform Earthqu 11:93-96

Publisher's Note Springer Nature remains neutral with regard to jurisdictional claims in published maps and institutional affiliations. 